\title{
India pushes for common responsibility
}

\author{
Rajendra K. Pachauri says that India wants to be a constructive partner in Copenhagen negotiations on climate \\ change. The country is taking domestic action even though it cannot accept mandatory emissions limits.
}

\begin{abstract}
ndia expects a strong agreement at December's United Nations climate conference in Copenhagen for several reasons. First, the country is very vulnerable to the effects of climate change, both those projected to occur within its own territory and those in neighbouring countries. Bangladesh, for instance, with a population of 160 million people is extremely vulnerable to sea level rise. This, along with the growing intensity and frequency of cyclones and other extreme events could result in large numbers of migrants fleeing to India. Equally serious are the problems associated with glaciers melting in the Hindu Kush region. Most of the rivers in northern India originate in these
\end{abstract} glaciers, and a decline in river flows because of reduced glacial mass would lead to water scarcity for India and its neighbours. Climate change is also likely to directly affect agricultural production, because there is growing evidence that some agricultural crops are seeing a decline in yields due to climate change, most

oे notably wheat crops grown in North India (H. Pathak et al. Field Crops Res. 80, 223-234; 2003). Consequently, India has a vital stake in the stabilization of Earth's climate system.

Second, India is not solely interested in seeing global emissions adequately reduced as soon as possible. The country also has a direct interest in adaptation measures for coping with projected climate change, which is now inevitable because of the existing inertia in the climate system. India feels strongly that on the basis of historical responsibility and considerations of equity, developed countries should provide financial support for adaptation in developing countries. It is no coincidence that the subject of adaptation first emerged as a prominent issue in international climate negotiations held in New Delhi in 2002. Since then, the debate has gone further, with a number of developing countries joining in the demand for adequate financial support for this purpose from developed nations.

India has been one of the strongest proponents of the principle of 'common but differentiated responsibility' included in the United Nations Framework Convention on Climate Change, demanding action strictly on this basis. In India's view, therefore, the Copenhagen agreement should involve major cuts in greenhouse-gas emissions by the developed countries, and should clearly articulate the support that the developed countries will provide for access to low-carbon technologies in the developing world. Over time, this will help developing countries implement measures to limit their own emissions.

Within the limited time available, India can perhaps play a constructive part in forging an agreement in Copenhagen. As a matter of principle, India will firmly dismiss demands from developed nations that their proposed emissions cuts should, in any way, be contingent on rapidly developing economies, such as India and China, committing themselves to emissions limits before 2020. But to demonstrate the country's seriousness towards shared action, India has a domestic programme - the National Action Plan on Climate Change (NAPCC) - that it could, at an appropriate stage of the negotiations, offer as part of a global package of commitments. The NAPCC was released by India's Prime Minister Manmohan Singh in June. It was inspired, in no small part, by the attention given to the 2007 Fourth Assessment Report of the Intergovernmental Panel on Climate Change.

The plan focuses on achieving a pattern of sustainable development while dealing comprehensively with the challenge of climate change. In Copenhagen, India should reject any imposition of measures for verification of goals achieved under the NAPCC, but might agree to annual international reporting. As a

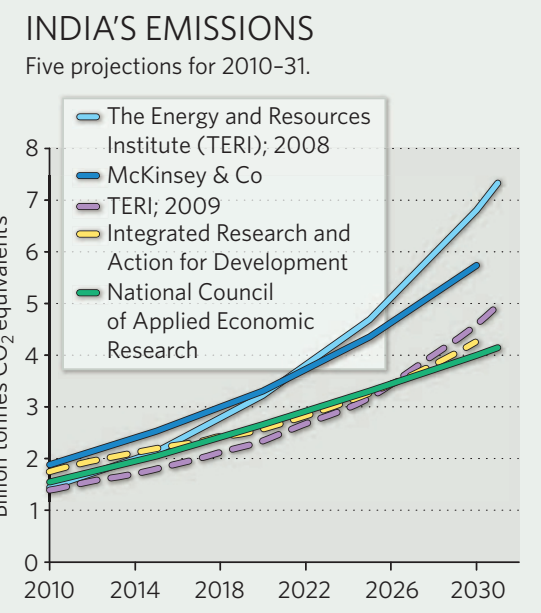

democracy with a vibrant civil society and a free press, India can be comfortable with such a provision because it would not be revealing any information that wouldn't be publicly available anyway. Still, to achieve the ambitious goals of the NAPCC will require unprecedented institutional changes within India to overcome the bureaucratic inertia that often stymies government plans. In particular, a greater role would be desirable for public-private partnerships and closer involvement of think tanks and research organizations in providing policy advice.

\section{Technological partnerships}

Some might say that India's projected three- or fourfold growth of emissions by 2030 under business as usual (see graphic) is much too high an estimate, but given the high economic growth rates achieved by India in recent decades this is a realistic projection. Without the development of low-carbon technologies and the transfer of technology, developing countries will continue to emulate the emissions-intensive growth patterns seen in the developed world. But alongside well-defined intellectual property rights, technological innovation can be created through partnerships between developed and developing countries at much lower cost than if these were driven solely by the developed world. It is for this reason that US companies such as GE are carrying out substantial research and development activities in India.

We need a more constructive spirit between developed and developing countries if we are to reach an effective agreement in Copenhagen. To achieve this, the leadership of developed nations must convince their public on the principles and scientific realities under which they will take proactive commitments. At the same time, major emerging economies such as India should not hesitate to put forward their own national action plans as part of global efforts, and which would help them achieve sustainable development. Rajendra K. Pachauri is chairman of the Intergovernmental Panel on Climate Change, director-general of The Energy and Resources Institute and director of the Yale Climate and Energy Institute.

e-mail: pachauri@teri.res.in

See Editorial, page 1027, and online at www.nature. com/roadtocopenhagen.

Join the discussion at go.nature.com/hzQ2MD. 